\title{
EAl Endorsed Transactions

\section{A Study of the Effects of First Person versus Third Person View in Educational Animation}

\author{
H. N. Dib ${ }^{1, *}$, N. Adamo-Villani ${ }^{1}$ and J. Yu ${ }^{1}$ \\ ${ }^{1}$ Department of Building Construction Management, Purdue University, 401 N. Grant St, West Lafayette
}

\begin{abstract}
The paper reports a study that investigated the effect of egocentric versus exocentric view in an educational animation whose goal was to teach undergraduate students the various tasks that a construction manager performs in the field. Specifically, the study aimed to determine the effect of perspective view on students' subject learning and preference. Findings show that while students have a preference on perspective view, the perspective view does not have a significant effect on students' learning outcomes
\end{abstract}

\begin{abstract}
Keywords: Educational animation; egocentric view; exocentric view.
Received on 28 September 2014, accepted on 23 March 2015, published on 14 July 2015

Copyright (C) 2015 H. N. Dib et al., licensed to ICST. This is an open access article distributed under the terms of the Creative Commons Attribution licence (http://creativecommons.org/licenses/by/3.0/), which permits unlimited use, distribution and reproduction in any medium so long as the original work is properly cited.
\end{abstract}

doi: 10.4108/el.2.6.e2

\section{Introduction}

Several studies found in the literature suggest that 3D computer animation can be an effective educational approach $[1,2,3,4]$. In most 3D animations, scenarios are presented in either first- or third-person view.

" $A$ view of $a$

$3 D$ world is the $2 D$ projection of the world presented to the user. It is entirely defined by the camera's location, angle, and field of view (FoV). A first-person view places the camera where the user's eyes would be in the virtual environment. A third-person view moves the camera away from the object of control, and often increases the angle of the camera to reduce occlusion" [5]. In animations where a character performs a sequence of tasks, either view can be used. In the first-person view, the camera is placed in front of the character's eyes and the animation is rendered as seen by the character; in the third-person view the camera is placed beside the character and the animation is rendered as if a third person is observing what the character is doing.
While several studies can be found in the literature on the effect of perspective view on user performance/preference in interactive games and simulations, to our knowledge, no study exists on the effect of perspective view in educational animations. The work reported in the paper aims to fill this gap; it investigated the effect of egocentric versus exocentric view in an educational animation whose goal was to teach undergraduate students the various tasks that a construction manager performs in the field. Specifically, the study aimed to determine the effect of perspective view on students' subject learning and students' preference. The paper is organized as follows: in section 2 we report existing studies on the effects of different perspective views on user experience. In section 3 we discuss benefits and drawbacks of educational animations and report prior work on animation for learning building construction. In section 4 we describe our study and discuss the results. Conclusion and future work are included in section 5 .

\footnotetext{
*Corresponding author. Email:nadamovi@purdue.edu
} 


\section{Existing studies on the effects of different perspective views on user experience}

Researchers have studied the effect of different perspective views in games and interactive simulations. A change in perspective view in a game/interactive simulation usually involves a change in the position and rotation of the center of the camera. In addition to visibility changes, a different perspective view provides the viewer with a different type of experience (e.g. more or less immersive) [6].

A study by Bateman et al. [5], shows that while there was no significant effect of perspective view on player's driving performance in a car racing game, there was an effect on player's preference. In Bateman's test, participants preferred the first-person view and predicted that they could perform better with such view. This may be because first a-person view provides a better sense of player immersion [6].

Salamin et al. [7] examined whether it is beneficial for users to have the choice to switch from first-person to thirdperson perspective in virtual and augmented reality environments. They asked participants to perform various tasks in both views including: walking through a gallery with obstacles, putting a ball into a cup of coffee, receiving and sending a rolling ball with the feet and with the hands. Results showed that while some actions, such as looking down or hand manipulations (catching a close object) are performed better in first-person perspective, others, such as interaction with moving objects, require a third-person perspective. This is due to the fact that a third person view offers a larger field of view, and therefore provides the user with more cues to evaluate the distances and anticipate or extrapolate the trajectory of mobile objects.

Salamin et al. [8] also conducted a study whose goal was to quantify the differences between the effects induced by training participants to the third-person and first-person perspectives in a ball catching task in virtual reality. Results of the experiment showed that for a certain trajectory of the ball, the performance of the participants after training to the third person perspective was similar to their performance after baseline perspective training. Performance after first person training varied significantly from both third person and baseline perspectives. The researchers concluded that usage of the third person perspective in training and learning methods might prove to be more effective as it facilitates performances and leads to quicker adaptation of distance evaluation in the extra personal space.

Anquetil and Jeannerod [9] conducted a study in which subjects simulated a grasping action with two levels of difficulty. In one condition, they simulated the movement from their own, first person perspective, while in the other condition they simulated the same movement made by a person facing them (third person perspective). The time to complete the movement was found to be almost the same in the two conditions and a similar difference in time between easy and difficult grasps was retained in the two conditions. These results show that a self-generated and an observed action share the same representation and this representation can be used from different perspectives.

Pazuchanics [10] investigated two methods to increase UGV (uninhabited ground vehicles) operators' performance. Typically, UGV cameras provide their operators with a very narrow, field of view (FOV) and a first-person camera perspective. His study investigated two methods for providing an operator with additional contextual information: widening the FOV and capturing a third-person perspective of the vehicle in its environment. Findings show that the additional information provided by either method can increase navigation performance. Of the two methods, widening the FOV produced the greatest performance benefit, however capturing a third-person perspective may also facilitate certain aspects of navigation. The benefits associated with each method were found to be cumulative and therefore ideal video displays may incorporate both methods.

\section{Educational Animations}

Researchers have studied the influence of computer animations on students' learning through various experiments and have achieved mixed results. While some experiments show that animation can be an effective pedagogical tool, e.g. $[11 ; 12 ; 13]$, other studies suggest that animations can be distracting with little or no positive effect on learning, e.g. [14; 15].

Those researchers who believe computer animation is an effective instructional device argue that the main strength of animation is the fact that it can represent information in different codes: images, words (text or narration) and motion [3]; several codes are more influential than one in learning. Moving graphics can attract the viewers and attain audience motivation [16], and animation can play an effective instructional role by engaging the viewer, guiding attention, representing motion-related knowledge, and explaining complex concepts in simple steps [17]. Another benefit of animation is its ability to explain a dynamic and changing process. Through animations, students can develop better mental pictures of an activity or a procedure, which leads to a higher understanding of complex concepts $[3 ; 4$; $18]$.

Many of the researchers who question the pedagogical efficacy of animation argue that animations, especially $3 \mathrm{D}$, can lead to a cognitive overload and, subsequently, a decrease in learning $[19,20]$. A few believe that animations may be ineffective because they violate the second principle of good graphics, the Apprehension Principle, according to which graphics should be accurately perceived and appropriately conceived. "Animations can be too complex or too fast to be accurately perceived. ...Animations may be more effective than comparable static graphics in situations other than conveying complex systems, for example, for real time reorientations in time and space" [3].

A few studies on the use of 3D animation/simulation for teaching/learning building construction can be found in the literature. Kamat and Martinez [21, 22] developed a 3D text 
file driven visualization system, the Dynamic Construction Visualizer, that enables users to visualize both the construction processes and the evolving products in $3 \mathrm{D}$. The researches argue that the main advantage of using simulation to model construction operations is to obtain insights into the consequences of using different techniques and strategies, thus helping the planner in making the most advantageous decisions. Construction simulation systems can provide users with detailed information such as statistical production charts, resource usability, and breakdown times in the modeled system. Furthermore, visualizing simulated construction operations in $3 \mathrm{D}$ can significantly help in establishing the credibility of simulation models.

Messner and Horman [23] conducted several experiments that demonstrated that students can develop a more in-depth understanding of the construction process and construction planning by using advanced $3 \mathrm{D}$ visualization tools. Perdomo et al. [24] carried out a study that investigated the advantages of $3 \mathrm{D}$ modeling and simulation, as compared to static 2D drawings, in understanding construction assemblies and details. Findings showed that it was easier for the students to identify the assemblies, the assemblies' profiles and shapes and the connection details using the 3D models than the $2 \mathrm{D}$ drawing sets. In addition, the animation feature in the $3 \mathrm{D}$ viewing application helped students to trace the sequence of construction. Dib et al. [25] developed an interactive $3 \mathrm{D}$ virtual environment for learning surveying practices for building construction. A study with a group of undergraduate students in the Building Construction Management Department at Purdue University demonstrated the pedagogical efficacy of the 3D tool Dib et al. [26].

\section{Description of study}

The objective of this study was to investigate the effect of different perspective views, in educational 3D animations, on students' learning of building construction management tasks, and students' preference. The study compared two types of computer animations: one rendered using an egocentric perspective view, and one rendered using an exocentric perspective view. The animations presented to the participants were designed for an undergraduate course in building construction management. The content was identical and focused on the tasks that a building construction manager needs to perform on a construction site. The first person view animation can be accessed at: http://www.youtube.com/watch?v=g4gAlqJv9F4\&feature=y outu.be

The third person view animation can be accessed at: http://www.youtube.com/watch?v=kW7SAZllumo\&feature =youtu.be

Figure 1 shows frames extracted from both animations.

The study used a quantitative approach and tested the hypotheses listed below.

In instructional 3D animations for building construction management education:
H01: There is no difference in the learning effect between first-person perspective view and third-person perspective view.

Ha1: There is a difference in the learning effectiveness between first-person and third-person perspective view.

H02: There is no correlation between the learning effectiveness of a specific perspective view and concept/task being presented.

Ha2: There is a correlation between the learning effectiveness of a specific perspective view and concept/task being presented.

H03: Users do not have preference on perspective view

Ha3: Users have preference on perspective view.

H04: The student preference of perspective view does not change based on the concepts/tasks being presented.

Ha4: The student preference of perspective view changes based on the concepts/tasks being presented.

In addition, the study also tested the following hypotheses to determine whether watching the animation, either first or third person view, had an effect on students' learning:

Ha5: There is a difference in subject learning between students who watched the educational animation (first or third person view) and those who did not watch the animation and used the textbook.

H05: There is no difference in subject learning between students who watched the educational animation (first or third person view) and those who did not watch the animation and used the textbook.

For hypotheses 1, 2 and 5, the learning objective considered by the study was the student's ability to demonstrate knowledge and understanding of the tasks that a building construction manager performs on a construction site (these tasks are listed in the left column of table 1). We measured this learning objective using pre and post educational intervention competency testing. The study included three independent variables: the first-person view animation, the third-person view animation, and the traditional textbook. The subjects were divided in three groups: control group (1)--exposed to text book, experimental group (2)--exposed to first-person view animation, and experimental group (3)--exposed to thirdperson view animation. The dependent variables were the mean scores of the test in the three groups after the experiment.

To test hypotheses 4 and 5 , a survey including questions about the subjects' experience was administered to the students.

The experiment included two phases. In phase 1 the study collected data on students' preference and formative feedback on the animation. In phase 2 the study collected summative data on students' learning outcomes.

\subsection{Phase 1}

The objective of phase 1 was to test hypotheses 3 and 4 and collect formative feedback.

Subjects: 34 undergraduate students enrolled in a Building Construction Management program. All subjects 
had prior knowledge of the educational content presented in the animation.

Testing instrument: An online survey comprised of 19 multiple-choice questions and 1 open-ended question. The first question asked the students whether the animation could have helped them learn the content more efficiently. The second question asked about their overall perspective view preference. The following 16 questions asked about perspective view preference (and prediction of learning more efficiently from this view) for each individual task simulated in the animation. The open-ended question prompted students for comments and suggestions for improvements.

Procedure: Each subject sat in front of a monitor displaying the two animations side by side (as shown is Figure 1). Subjects had the option to play the animations as many times as they wanted. After watching the animations, the subjects completed the online survey and submitted their answers.
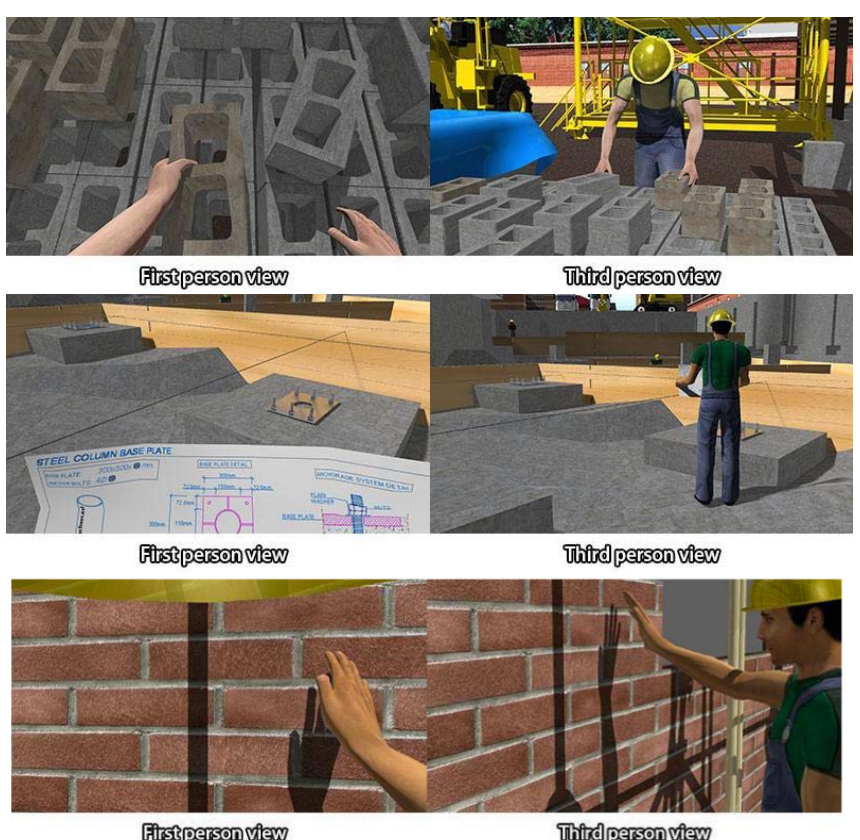

Figure 1. Frames extracted from the first person and third person view animations

Findings and discussion: Findings show that $67 \%$ of the subjects thought the animations are effective tools for learning the content. Results also show that participants have a preference on perspective view in computer animation. The distribution of the response for general preference shows that $20 \%$ of the participants prefer the first-person view, $73 \%$ of the participants prefer the thirdperson view, and $7 \%$ do not have a preference. Findings demonstrate that subjects' preference on perspective view changes based on the type of task being simulated. For example, participants strongly preferred the first-person view when the task depicted in the animation is about checking the footing size and the location of anchor bolts. Whereas users indicated stronger preference for the thirdperson view when the task focuses on verifying the top of beam elevations, checking the elevation at both ends of sloped beams, checking the vertical alignment of the wall after building CMU blocks and coordinating the anchor bolt layout with concrete pour schedule.

\section{Table 1. Findings from the survey on perspective view} preference

\begin{tabular}{|c|c|c|c|}
\hline Question & Yes & No & Not Sure \\
\hline $\begin{array}{l}\text { Watching the animations would have } \\
\text { helped me learn the content }\end{array}$ & $67 \%$ & $10 \%$ & $23 \%$ \\
\hline & $\begin{array}{l}\text { 1.First } \\
\text { Person } \\
\text { View }\end{array}$ & $\begin{array}{l}\text { 2.Third } \\
\text { Person } \\
\text { View }\end{array}$ & $\begin{array}{c}\text { 3.No } \\
\text { Preference }\end{array}$ \\
\hline Overall preference of perspective view & $20 \%$ & $73 \%$ & $7 \%$ \\
\hline $\begin{array}{l}\text { 1. Coordinate the anchor bolt layout } \\
\text { with concrete pour schedule. }\end{array}$ & $30 \%$ & $67 \%$ & $3 \%$ \\
\hline $\begin{array}{l}\text { 2. Check footing size and location of } \\
\text { anchor bolts. }\end{array}$ & $73 \%$ & $24 \%$ & $3 \%$ \\
\hline 3. Check footing size. & $70 \%$ & $20 \%$ & $10 \%$ \\
\hline $\begin{array}{l}\text { 4. Establish anchor bolt survey } \\
\text { requirements and verify elevation of } \\
\text { anchor bolt. }\end{array}$ & $33 \%$ & $60 \%$ & $7 \%$ \\
\hline $\begin{array}{l}\text { 5. Check the typical details (in the } \\
\text { floor slab or steel supports beneath the } \\
\text { opening) for additional reinforcing for } \\
\text { opening. }\end{array}$ & $30 \%$ & $60 \%$ & $10 \%$ \\
\hline $\begin{array}{l}\text { 6. Verify top of beam elevations and } \\
\text { check elevation at both ends of sloped } \\
\text { beams. }\end{array}$ & $13 \%$ & $74 \%$ & $13 \%$ \\
\hline $\begin{array}{l}\text { 7. Materials must be properly handled } \\
\text { stored and prepared. }\end{array}$ & $30 \%$ & $53 \%$ & $17 \%$ \\
\hline $\begin{array}{l}\text { 8. Units must be laid with full head } \\
\text { and bed joints, joints must be tooled } \\
\text { properly. }\end{array}$ & $27 \%$ & $56 \%$ & $17 \%$ \\
\hline $\begin{array}{l}\text { 9. CMU alignment, CMU color } \\
\text { inspect units and the mortar, texture of } \\
\text { the units, check pattern by the type of } \\
\text { bond and the unit }\end{array}$ & $40 \%$ & $50 \%$ & $10 \%$ \\
\hline $\begin{array}{l}\text { 10. Materials must be properly } \\
\text { handled stored and prepared, check } \\
\text { walls' layout and openings location. }\end{array}$ & $50 \%$ & $37 \%$ & $13 \%$ \\
\hline $\begin{array}{l}\text { 11. If steel is to be fireproofed, inspect } \\
\text { thickness of fireproofing material. }\end{array}$ & $23 \%$ & $63 \%$ & $14 \%$ \\
\hline $\begin{array}{l}\text { 12. Check location of expansion joints } \\
\text { and make sure they are properly } \\
\text { caulked. }\end{array}$ & $23 \%$ & $60 \%$ & $17 \%$ \\
\hline $\begin{array}{l}\text { 13. Check joints are tooled and } \\
\text { finished properly. Example showing } \\
\text { Concave joints. }\end{array}$ & $37 \%$ & $33 \%$ & $30 \%$ \\
\hline $\begin{array}{l}\text { 14. Check joints are tooled and } \\
\text { finished properly. Example showing } \\
\text { weathered joints. }\end{array}$ & $47 \%$ & $33 \%$ & $20 \%$ \\
\hline $\begin{array}{l}\text { 15. Checking joints are tooled and } \\
\text { finished properly. Example showing } \mathrm{V} \\
\text { shape joints. }\end{array}$ & $37 \%$ & $53 \%$ & $10 \%$ \\
\hline $\begin{array}{l}\text { 16. Checking the vertical alignment of } \\
\text { the wall after building CMU blocks. }\end{array}$ & $23 \%$ & $77 \%$ & $0 \%$ \\
\hline
\end{tabular}

In general, users preferred the first-person view when the environment is not relevant and the simulated task requires 
focusing on a small object/detail. In contrast, the thirdperson view is preferred for tasks that require understanding of the environment or of a larger system/area. One participant commented that the third person view is very helpful to students who are inexperienced as it provides an "effective overview of the construction site and puts the various activities into context." A summary of results is included in table 1.

\subsection{Phase 1}

The objective of phase 2 was to test hypotheses 1,2 and 5 . Subjects: 66 students enrolled in a Building Construction Management undergraduate course.

Testing instruments: a 7-question test including 6 short essay questions and 1 true/false question. The test focused on the "STEEL" part of the animation, e.g. tasks 1- 6 and 11 listed in the left column of table 1.

Procedure: all subjects were given a pre-test to assess their basic knowledge of the educational content. After the pre-test, a randomized complete block design was used to divide the subjects into three groups with similar preknowledge: control group (1) -- traditional textbook; experimental group (2)--first person view animation, and experimental group (3)--third person view animation. One week after the pre-test all students were given a 45-minute lecture on the content. One week after the lecture, group 2 interacted with the first person view animation for 30 minutes in the lab; group 3 interacted with the third person view animation for 30 minutes in the lab; and group 1 reviewed the content using the textbook for $30 \mathrm{~min}$. Two weeks later, all participants were administered a post-test which was identical to the pre-test.

Findings: Two One-way ANOVA were performed to compare the differences in pre-test and post-test scores for each group. Ten students missed the post-test (eight of them from Group 1), so their data was discarded.

Results show that attending the lecture and watching the animation ( $1 \mathrm{st}$ or $3^{\text {rd }}$ person) led to an increase in subject content learning by $4.28 \%$ and $4.27 \%$ respectively, compared to the control group. Group 1 (control)'s post-test score increased by $17.47 \%$ from pre-test. Experimental group 2 (1st person) post-test score increased by $21.74 \%$, while for group 3 (third person), the increase was of $21.75 \%$. Results show that the difference in learning gains between the two experimental groups is not statistically significant. They also show that the difference in total learning gains between the control and the experimental groups is not statistically significant $(\mathrm{F}(2,53)=0.976$, p>.05; M (Group 1) $=0.3429$ SD (Group 1) $=0.10535 ; \mathrm{M}$ $($ Group 2) $=0.3833$; SD (Group 2) $=0.08266$; M (Group 3) $=0.3857$; SD $($ Group 3$)=0.10385$;). Table 2 shows a summary of results.

In summary, perspective view did not have an effect on students' learning outcomes, although students had expressed a preference for third-person view and had predicted to learn more from this view for 5 out of the 7 tasks relevant to the test.
Table 2. Summary of findings

\begin{tabular}{|c|c|c|c|c|c|c|c|c|c|}
\hline & & $\mathrm{N}$ & Mean & $\begin{array}{l}\text { Std. } \\
\text { Dev. }\end{array}$ & $\begin{array}{l}\text { Std. } \\
\text { Error }\end{array}$ & $\begin{array}{r}95^{\circ} \\
\text { Confid } \\
\text { Interva } \\
\text { Mea } \\
\text { Lower } \\
\text { Bound } \\
\end{array}$ & $\begin{array}{l}\text { ence } \\
\text { ence } \\
1 \text { for } \\
\text { an } \\
\text { Upper } \\
\text { Bound }\end{array}$ & Min & Max \\
\hline \multirow[t]{4}{*}{ PreTest } & 1 & 22 & .1682 & $\begin{array}{c}.0748 \\
7\end{array}$ & $\begin{array}{c}.0159 \\
6\end{array}$ & .1350 & .2014 & .05 & .30 \\
\hline & 2 & 22 & .1659 & $\begin{array}{c}.0930 \\
8\end{array}$ & $\begin{array}{c}.0198 \\
4\end{array}$ & .1246 & .2072 & .00 & .40 \\
\hline & 3 & 22 & .1682 & $\begin{array}{c}.0779 \\
9\end{array}$ & $\begin{array}{c}.0166 \\
3\end{array}$ & .1336 & .2028 & .00 & .30 \\
\hline & Total & 66 & .1674 & $\begin{array}{c}.0810 \\
9\end{array}$ & $\begin{array}{c}.0099 \\
8\end{array}$ & .1475 & .1874 & .00 & .40 \\
\hline \multirow[t]{6}{*}{ PostTest } & 1 & 14 & .3429 & $\begin{array}{c}.1053 \\
5\end{array}$ & $\begin{array}{c}.0281 \\
6\end{array}$ & .2820 & .4037 & .15 & .50 \\
\hline & 2 & 21 & .3833 & $\begin{array}{c}.0826 \\
6\end{array}$ & $\begin{array}{c}.0180 \\
4\end{array}$ & .3457 & .4210 & .20 & .55 \\
\hline & 3 & 21 & .3857 & $\begin{array}{c}.1038 \\
5\end{array}$ & $\begin{array}{c}.0226 \\
6\end{array}$ & .3384 & .4330 & .20 & .60 \\
\hline & Total & 56 & .3741 & $\begin{array}{c}.0967 \\
6 \\
\end{array}$ & $\begin{array}{c}.0129 \\
3 \\
\end{array}$ & .3482 & .4000 & .15 & .60 \\
\hline & \multicolumn{9}{|c|}{ ANOVA } \\
\hline & & & & $\begin{array}{l}\mathrm{n} \text { of } \\
\text { ares } \\
\end{array}$ & $\mathrm{Df}$ & $\begin{array}{l}\text { Mean } \\
\text { Square }\end{array}$ & $\mathrm{F}$ & & Sig \\
\hline \multirow[t]{3}{*}{ PreTest } & Betwee & Groups & & 00 & 2 & .000 & .006 & & 994 \\
\hline & Withir & Groups & & 27 & 63 & .007 & & & \\
\hline & & & & 27 & 65 & & & & \\
\hline \multirow[t]{3}{*}{ PostTest } & Betwee & Groups & & 18 & 2 & .009 & .976 & & .384 \\
\hline & Withir & Groups & & 97 & 53 & .009 & & & \\
\hline & & tal & & 15 & 55 & & & & \\
\hline
\end{tabular}

\section{Conclusion and future work}

In this paper, we have explored the effect of perspective view in educational animations on students' learning of building construction management tasks, and on students' preference. Results show that students have a preference on perspective view, however perspective view does not influence learning outcomes. The study also investigated the efficacy of animation as a teaching/learning tool. Findings show that animation led to higher learning gains than traditional teaching/learning methods, although the difference in learning was not statistically significant in this study. This finding adds to the body of research that suggests that animation can be an effective educational approach.

Our study had one main limitation: a relatively small sample size. Because of the limited number of participants, we cannot generalize the results and we can only suggest that perspective view does not have an influence on students' learning in educational animations. In order to build stronger evidence, additional studies with larger pools of participants, in different subject domains and in different settings will need to be conducted. 


\section{References}

[1] Rias, R.M., Zaman, H. B. (2012). Can different types of animation enhance recall and transfer of knowledge? A case study on a computer science subject. Asian Journal of Teaching and Learning in Higher Education, vol. 4, issue 1, pp. 32-43

[2] Khalil, M., Johnson, T., Lamar, C. (2005). Comparison of computer based and paper based imagery strategies in learning anatomy, Clinical Anatomy, vol. 18, pp. 457-464

[3] Tversky, B., Morrison, J.B., Betrancourt, M. (2002). Animation: can it facilitate? International Journal of Human- Computer Studies, vol. 57, issue 4, pp. 247262

[4] Taylor, M. J., Pountney, D. C., Baskett, M. (2008). Using animation to support the teaching of computer game development techniques, Computers \& Education, vol. 50, issue 4, pp. 1258-1268

[5] Bateman, S., Doucette, A., Xiao, R., Gutwin, C., Mandryk, R.L., Cockburn, A. (2011). Effects of view, input device, and track width on video game driving. In: Proceedings of Graphics Interface 2011, pp. 207214. Canadian Human-Computer Communications Society

[6] Rouse III, R.: What's your perspective? ACM SIGGRAPH Computer Graphics vol. 33, issue 3, pp. 9-12. ACM New York, NY USA (1999)

[7] Salamin, P., Thalmann, D., Vexo, F.: The benefits of third-person perspective in virtual and augmented reality? In: Proceedings of the ACM symposium on Virtual reality software and technology, pp. 27-30. ACM New York, NY, USA (2006)

[8] Salamin, P., Tadi, T., Blanke, O., Vexo, F., Thalmann, D.: Quantifying effects of exposure to the third and first-person perspectives in virtual-reality-based training., IEEE Transactions on Learning Technologies Vol. 3, issue 3, pp. 272-276. IEEE Computer Society (2010)

[9] Anquetil, T., Jeannerod, M.: Simulated actions in the first and in the third person perspectives share common representations. Brain research, vol. 1130, pp. 125-129 (2007)

[10] Pazuchanics, S.L.: The effects of camera perspective and field of view on performance in teleoperated navigation. In: Proceedings of the Human Factors and Ergonomics Society Annual Meeting, vol. 50, issue 16, pp. 1528-1532. SAGE Publications (2006)

[11] Dooley, K. E., Stuessy, C., Magill, J., Vasudevan, P. (2000). Cognitive and affective outcomes of animation on asynchronous learning of agricultural science concepts, Proc. of the 27th annual National Agricultural Education Research conference, San Diego, CA

[12] English, B.M., Rainwater, S. B., (2006). The effectiveness of animations in an undergraduate operating systems course, Journal of Computing Sciences in Colleges, 21(5), pp. 53-59

[13] Wilson, F., Dwyer, F. (2001). Effect of Time and Level of Visual Enhancement in Facilitating Student Achievement of Different Educational Objectives, International Journal of Instructional Media, 28(2), pp. $59-67$
[14] McGregor, K. W., Fraze, S., Baker, M., Drueckhammer, D., Lawver, D. (2003). Effects of computer animated instruction upon low-level cognition of undergraduates in an agricultural power technology course, Proc. of the 22nd Annual Western Region Agricultural Education Research Conference, Portland, Oregon, 2003

[15] Park., O., Hopkins, R., (1993). Instructional conditions for using dynamic displays: A review, Instructional Science, 21, pp. 427-449

[16] Sirikasem, P., Shebilske, W.L., (1991). The perception and metaperception of architectural designs communicated by video-computer imaging, Psychological Research/ Psychologische Forschung, 53 , pp. $113-126$

[17] Park, O. (1998). Visual Displays and Contextual Presentations in Computer Based Instruction, Educational Technology Research \& Development, 46 (3), pp.18-32

[18] Wu, K., Shah, P. (2004). Exploring visuospatial thinking in chemistry learning, Science Education, 88, pp. 465- 492

[19] Gerjets, P., Scheiter, K. (2003). Goal configurations and processing strategies as moderators between instructional design and cognitive load: Evidence from hypertext-based instruction, Educational Psychologist, 38, pp. 33-41

[20] Paas, F., Van Gerven, P. W. M., Wouters, P. (2007). Instructional efficiency of animation: Effects of interactivity through mental reconstruction of static key frames. Applied Cognitive Psychology, 21(6), pp.783-793

[21] Kamat, V. R., \& Martinez, J. C. (2000). 3D visualization of simulated construction operations. Proceedings of the $32 \mathrm{nd}$ conference on winter simulation. pages 1933-1937

[22] Kamat, V. R., \& Martinez, J. C. (2001). Visualizing simulated construction operations in 3D. Journal of Computing in Civil Engineering, 15(4), 329-337

[23] Messner J.I, and Horman, M.J. (2003). Using Advanced Visalization Tools to Improve Construction Education. Proc. of CONVR 2003, Virginia Tec, Sept 24-26, 2003

[24] Perdomo, J.L., Shiratuddin, M.F., Thabet, W., and Ananth, A. (2005). Interactive 3D Visualization As A Tool For Construction Education. Proc. of ITHET $6^{\text {th }}$ Annual International Conference, July 7-9, 2005,Juan Dolio, Dominican Republic. Paper FB4-23

[25] Dib, H., Adamo-Villani, N., \& Garver, S. (2014). An interactive virtual environment for learning differential leveling: development and initial findings. Advances in Engineering Education (ASEE), Fall 21014, Vol. 4, Issue 2.

[26] Dib, H., \& Adamo-Villani, N. (2011). An innovative software application for Surveying Education. Journal of Computer Applications in Engineering Education. DOI: $10.1002 /$ cae. 20580 